\title{
Lipids modulate acetic acid and thiol final concentrations in wine during fermentation by Saccharomyces cerevisiae $\times$ Saccharomyces kudriavzevii hybrids
}

\author{
Amandine Deroite ${ }^{1,2}$, Jean-Luc Legras ${ }^{2}$, Peggy Rigou $^{2}$, Anne Ortiz-Julien ${ }^{1}$ and Sylvie Dequin ${ }^{2 *}$ (i)
}

\begin{abstract}
Saccharomyces cerevisiae $\times$ Saccharomyces kudriavzevii hybrids are typically used for white wine fermentation because of their cryotolerance. One group of these hybrids presents a unique ability to release thiol varietal aroma products as well as excessive amounts of acetic acid under specific conditions, which is detrimental for wine organoleptic quality. The aim of this work is to better assess the effects of lipids, sugar concentrations and temperature on the production of acetic acid and thiols during wine fermentation. To this end, we used a Box-Behnken experimental design and response surface modeling on the production of acetic acid and thiols in S. cerevisiae $\times$ S. kudriavzevii hybrids from the Eg8 family during fermentation of a synthetic must. We showed that these hybrids produced lower levels of acetic acid when the initial lipid concentration was increased, whereas they produced greater levels when the initial sugar concentration was high. Moreover, we found that lipids had a positive impact on the final concentrations of 4-methyl-4-mercaptopentan-2-one and 3-mercaptohexan-1-ol (3MH), giving box tree and citrus flavors, respectively. The increase of $3 \mathrm{MH}$ was concomitant with a decrease of 3-mercaptohexyl acetate (3MHA) characterized by a passion fruit aroma, indicating that lipid addition reduces the rate of $3 \mathrm{MH}$ acetylation into $3 \mathrm{MHA}$. These results highlight the key role of lipid management in acetic acid metabolism and thiol release by S. cerevisiae $\times$ S. kudriavzevii hybrids and underline its technological interest in alcoholic fermentation to avoid the overproduction of volatile acidity while favoring the release of volatile thiols.
\end{abstract}

Keywords: Saccharomyces cerevisiae $\times$ Saccharomyces kudriavzevii hybrids, Acetic acid, Thiols, Lipids, Box-Behnken experimental design, Wine fermentation

\section{Introduction}

Saccharomyces cerevisiae wine strains form a cluster apart from $S$. cerevisiae strains from different origins, presenting genetic variations compared to S. cerevisiae from other ecological niches (Legras et al. 2007, 2018; Liti et al. 2009; Peter et al. 2018). This is a consequence of the historical and demographic events that the wine yeast populations have faced (Warringer et al. 2011). In addition to the population history, the constraints of the

*Correspondence: sylvie.dequin@inra.fr

2 SPO, Univ Montpellier, INRA, Montpellier SupAgro, Montpellier, France Full list of author information is available at the end of the article grape must composition and stresses imposed by wine fermentation conditions, such as high sugar concentrations, low $\mathrm{pH}$, lipid and nitrogen deficiencies and high concentrations of ethanol, have led to specific adaptations, including interspecific hybridization (for a review, see Marsit and Dequin 2015). Many spontaneous interspecific hybridization events between $S$. cerevisiae and other Saccharomyces species have been detected among the isolates obtained from fermentations performed in cold climate areas. This is the case of $S$. cerevisiae $\times S a c$ charomyces kudriavzevii hybrids, which have been frequently isolated in low-temperature fermentations (for a 
review on $S$. cerevisiae $\times S$. kudriavzevii hybrids, see Peris et al. 2018). Indeed, these hybrids combine the fermentative performances of $S$. cerevisiae and the cryophilic properties of $S$. kudriavzevii, which presents a lower optimal growth temperature (Belloch et al. 2008; Sampaio and Goncalves 2008; Salvadó et al. 2011). For example, a group of $S$. cerevisiae $\times S$. kudriavzevii hybrids spread throughout Northern European vineyards, where grapes are frequently harvested in the autumn when temperatures are cooler (Erny et al. 2012). The Eg8 industrial strain, which belongs to this group, was originally isolated in 1979 from a vat fermenting at low temperature in Alsace (France) and was described as a triploid S. cerevisiae $\times$ S. kudriavzevii hybrid for the first time in 2012 (Erny et al. 2012). This strain and its variants, further called the Eg8 family, are mainly used in white wine fermentations because of their cryophilic characteristics and because of their ability to release a high amount of varietal thiols under oenological conditions (Murat et al. 2001). These thiols contain aromatic compounds that produce sought-after aromas characteristic of Sauvignon Blanc white wines but are also contained in many white grape varieties such as Gewurztraminer, Riesling or Petit and Gros Manseng grape juices (Dagan 2006; Roland et al. 2010). Each varietal thiol brings a particular aroma to the wine: 4-methyl-4-mercaptopentan2-one (4MMP) is characteristic of box tree aroma, while 3-mercaptohexan-1-ol (3MH) and 3-mercaptohexyl acetate (3MHA) give fruity aromas, citrus and passion fruit flavors, respectively. 4MMP and $3 \mathrm{MH}$ are mainly liberated in the medium from odorless precursors present in the grape must (Cysteine-4MMP, Glutathione-4MMP, Cysteine-3MH, and Glutathione-3MH) owing to a yeast beta-lyase (Howell et al. 2005; Thibon et al. 2008; Holt et al. 2011; Roncoroni et al. 2011), and 3MH can be acetylated into 3MHA by Atf1p, an acetyltransferase produced by the yeast (Roland et al. 2011).

However, in addition to the desired ability to release thiols and their good ability to complete alcoholic fermentation, it has been reported that strains from the Eg8 family sometimes produce excessive concentration of acetic acid $[>0.7 \mathrm{~g} / \mathrm{L}$ according to Ribéreau-Gayon et al. (2006)] under specific oenological conditions, leading to an unacceptable organoleptic quality of wine. Among the hybrids from the Eg8 family, two groups can be distinguished: the higher acetic acid producers which are ancestral strains and the lower acetic acid producers which have been obtained by UV mutagenesis from the first cluster, and selected for lower acetic acid production.

During alcoholic fermentation, S. cerevisiae produces acetic acid via the pyruvate dehydrogenase (PDH) bypass, which converts pyruvic acid to acetyl coenzyme A (acetyl-CoA) through three enzymatic steps catalyzed by pyruvate decarboxylase, acetaldehyde dehydrogenase $(\mathrm{ACDH})$ and acetyl-CoA synthase (Holzer and Goedde 1957; Pronk et al. 1994; Remize et al. 2000). Acetaldehyde produced from pyruvic acid is converted to acetic acid mainly by the cytosolic enzymes Ald6p and Ald4p and the mitochondrial enzyme Ald5p, leading to NADPH regeneration (Remize et al. 2000; Saint-Prix et al. 2004).

It is already known that acetic acid production by $S$. cerevisiae during wine fermentation is impacted by several environmental factors, such as the initial sugar concentration (Erasmus and van Vuuren 2009; Monk and Cowley 1984), lipid content (Belviso et al. 2004; Landolfo et al. 2010; Ochando et al. 2016; Rollero et al. 2015; Thurston et al. 1981; Varela et al. 2012) and temperature (Beltran et al. 2008; Monk and Cowley 1984). However, the combined effects of these environmental factors on acetic acid production in yeast have never been studied, and the factors affecting the production of this acid in $S$. cerevisiae $\times$ S. kudriavzevii hybrids are unknown.

The objective of this work is to study the combined effects of three environmental parameters, sugar concentration, lipid content and temperature, on acetic acid production and thiol liberation by $S$. cerevisiae $\times S$. kudriavzevii hybrids of the Eg8 family. A Box-Behnken experimental design was used to limit the number of experiments and to build a model that described the effects of these environmental factors and their interactions (Box and Behnken 1960). This model allows the illustration of the results through response surface, highlighting the optimal conditions to decrease acetic acid production and enhance thiol liberation during wine fermentation performed by a S. cerevisiae $\times S$. kudriavzevii hybrid. Results obtained with the Box-Behnken experimental design were then validated in natural grape must using a complete experimental design.

\section{Materials and methods \\ Yeast strains and media}

The $S$. cerevisiae $\times$ S. kudriavzevii wine yeast strains used in this work are described in Table 1 and are natural hybrids from the group Eg8 described previously (Erny et al. 2012).

Strains were maintained as frozen stocks [YPD: yeast extract $1 \%$ weight/volume $(\mathrm{w} / \mathrm{v})$, peptone $1 \% \mathrm{w} / \mathrm{v}$ and glucose $2 \% \mathrm{w} / \mathrm{v}$ with glycerol $15 \% \mathrm{v} / \mathrm{v}$ ] at $-80{ }^{\circ} \mathrm{C}$ or for short-term storage on YPD agar medium at $+4{ }^{\circ} \mathrm{C}$. Fermentation flasks were inoculated with $10^{6}$ cells $/ \mathrm{mL}$ from an overnight YPD culture.

\section{Fermentation media and conditions}

Fermentations of the Box-Behnken experimental design were performed in synthetic medium (SM) with $200 \mathrm{mg} / \mathrm{L}$ yeast available nitrogen (YAN), which mimics 
Table 1 S. cerevisiae $\times$ S. kudriavzevii hybrids used in the study

\begin{tabular}{|c|c|c|}
\hline Name & Origin & Yeast collection \\
\hline Eg8_V0 & Low temperature (i.e., $15^{\circ} \mathrm{C}$ ) fermenting vat, Eguisheim (Alsace, France) & INRA Montpellier \\
\hline Eg8_V2 & Mutant strain of the Eg8_V0 strain obtained by UV mutagenesis, selected for its lower acetic acid production & Lallemand \\
\hline Eg8_V3 & Mutant strain of the Eg8_V0 strain obtained by UV mutagenesis, selected for its lower acetic acid production & INRA Montpellier \\
\hline Eg8_V4 & Alsace (France) & Lallemand \\
\hline
\end{tabular}

a standard grape juice, following protocols described by Bely et al. (1990). The pH was adjusted to 3.3 with $10 \mathrm{M}$ $\mathrm{NaOH}$.

We used three sugar concentrations of $50 \%$ glucose and $50 \%$ fructose $(170,210$ and $250 \mathrm{~g} / \mathrm{L})$ and three levels of lipids $(0.0133,0.0333$ and $0.0533 \% \mathrm{v} / \mathrm{v})$, which were made from a $15 \mathrm{~g} / \mathrm{L}$ stock solution of phytosterols $(\beta$-sitosterol, Sigma Aldrich 85451, Saint-Louis, Missouri, États-Unis) in Tween80 (50\%) and ethanol (50\%). The final phytosterol concentrations were 2, 5 and $8 \mathrm{mg} / \mathrm{L}$, with 0.0067 , 0.0167 and $0.0267 \% \mathrm{v} / \mathrm{v}$ Tween 80 , respectively.

In the case of Eg8_V2, four thiol precursors (Nyseos, Montpellier, France) were added to SM medium to obtain the following final concentrations: $100 \mu \mathrm{g} / \mathrm{L}$ Cys-3MH; $500 \mu \mathrm{g} / \mathrm{L}$ Glu-3MH; $16 \mu \mathrm{g} / \mathrm{L}$ Cys-4MMP; and $3 \mu \mathrm{g} / \mathrm{L}$ Glu4MMP. Nyseos (Montpellier, France) performed thiol quantification for fermentations in natural grape must.

Fermentations in grape must were performed in triplicate with Sauvignon Blanc must from Gers, France (2017), which contained $180 \mathrm{~g} / \mathrm{L}$ sugar and $250 \mathrm{mg} / \mathrm{L}$ YAN and presented a turbidity of 140 nephelometric turbidity unit (NTU). This grape must was used in its natural state and subjected to decantation to achieve a turbidity of $20 \mathrm{NTU}$ and chaptalization to achieve a sugar concentration of $240 \mathrm{~g} / \mathrm{L}$ ( $50 \%$ fructose and $50 \%$ glucose). For some experiments, we tested three levels of lipids $(0.0133,0.0333$ and $0.0533 \% \mathrm{v} / \mathrm{v}$ of the stock solution previously presented) or the addition of Tween 80 alone to dissociate the effect of phytosterols from that of fatty acids on acetic acid production and thiol release.

Fermentations were performed in $330 \mathrm{~mL}$ flasks, containing $250 \mathrm{~mL}$ of medium continuously agitated by a magnetic stirrer (350 rpm). Anaerobiosis was obtained by bubbling argon for 20 min into the medium and was maintained through the use of fermentation locks. The tested temperatures were 16,20 and $24{ }^{\circ} \mathrm{C}$. Fermentations were monitored through the release of $\mathrm{CO}_{2}$, measuring the weight loss automatically every hour by robot-assistance (Box-Behnken experimental design in synthetic grape must) or manually twice a day (complete experimental design in natural grape must). When $80 \%$ of the initial sugar was consumed, fermentations were sampled for further analyses.

\section{Population counting and viability}

Cell concentrations were determined with an electronic particle counter (Beckman Coulter ZB-2, Margency, France). To avoid aggregates, which may bias cell counts, samples were sonicated by an ultrasonic generator before counting (Branson Sonifier 250, Danbury, Connecticut).

Cell viability was determined by flow cytometry using a C6 cytometer (Accuri, BD Biosciences, San Jose, CA). Propidium iodide (PI) from Calbiochem (Sigma-Aldrich, Saint-Louis, Missouri, États-Unis) was added to the cell suspension (final concentration: $1 \mu \mathrm{g} / \mathrm{mL}$ ). Since PI is a fluorescent nucleic acid stain that cannot penetrate intact cell membranes, fluorescence data for cells stained by PI allow determination of the percentage of intact and fragile cells among all cells (Tesnière et al. 2013).

\section{Determination of metabolite concentrations}

Acetic acid production was determined using HPLC (HPLC 1290 Infinity, Agilent Technologies, Santa Clara, California, USA) equipped with a Phenomenex Rezex ROA column (Agilent Technologies, Santa Clara, California, USA) at $60{ }^{\circ} \mathrm{C}$. This analysis also allowed for the determination of ethanol, glycerol, succinic acid, pyruvic acid, glucose and fructose concentrations. The column was resolved isocratically with $0.005 \mathrm{~N} \mathrm{H}_{2} \mathrm{SO}_{4}$ at a flow rate of $0.6 \mathrm{~mL} / \mathrm{min}$. Acetic acid and pyruvic acid concentrations were determined using a UV meter at $210 \mathrm{~nm}$, while the concentrations of all the other compounds were determined using a refractive index detector. Chromatograms were analyzed with the Agilent ChemStation software (Agilent Technologies, Santa Clara, California, USA). Analyses were performed in duplicate. When different sugar concentrations were studied, the metabolite production yields were determined instead of the concentration. This yield is expressed in $\mathrm{g}$ (or $\mathrm{mg}$ ) of metabolite produced per $\mathrm{g}$ of sugar consumed.

\section{Thiol quantification Sample storage}

To limit thiol oxidation during storage, samples were protected from oxygen by the addition of $50 \mathrm{mg} / \mathrm{L} \mathrm{SO}_{2}$. The suspensions were centrifuged for $10 \mathrm{~min}(3000 \mathrm{rpm})$ at $4{ }^{\circ} \mathrm{C}$. The supernatants were stored at $4{ }^{\circ} \mathrm{C}$ in $4 \mathrm{~mL}$ glass 
vials, completely filled, and quickly analyzed (with a maximum storage of 8 days for $3 \mathrm{MH}$ and $3 \mathrm{MHA}$ and 3 days for 4MMP).

\section{Standard solutions}

Quantifications were performed by stable isotope dilution assay (SIDA) using deuterated thiols at a set concentration $\left(4 \mathrm{MMP}_{\mathrm{d} 10} 0.1 \mu \mathrm{g} / \mathrm{L}, 3 \mathrm{MH}_{\mathrm{d} 2} 1 \mu \mathrm{g} / \mathrm{L}\right.$ and $3 \mathrm{MHA}_{\mathrm{d} 5}$ $0.3 \mu \mathrm{g} / \mathrm{L})$ and external calibration using natural thiols (Sigma-Aldrich, Saint-Louis, Missouri, États-Unis). The stock solutions were prepared in absolute ethanol.

4MMP quantification by solid-phase microextraction (SPME)gas chromatography-mass spectrometry (SPME-GC-MS/MS)

The 4MMP concentration in samples was quantified using a method published by Dagan et al. (2014), which was optimized for the use of triple quadrupole. The 4MMP was derivatized directly in the wine sample for $45 \mathrm{~min}$ at $55{ }^{\circ} \mathrm{C}$ using EDTA, L-cysteine and $\mathrm{O}$-methylhydroxylamine hydrochloride and then extracted by SPME for $30 \mathrm{~min}$ at $55^{\circ} \mathrm{C}$ on a DVB/CAR/PDMS fiber previously conditioned at $250{ }^{\circ} \mathrm{C}$ for $12 \mathrm{~min}$. Finally, the compounds were desorbed into the $\mathrm{GC}$ inlet at $250^{\circ} \mathrm{C}$ for $3 \mathrm{~min}$. Derivatized compounds were separated, identified and quantified using a Trace Ultra gas chromatograph (GC) equipped with a Triplus Autosampler and coupled with a triple quadrupole mass spectrometer TSQ 8000 detector from ThermoScientific (Austin, Texas, USA). Analysis and data treatment were monitored using the Xcalibur software (ThermoScientific, Austin, Texas, USA).

The GC was equipped with a J\&W DB-WAX (60 $\mathrm{m} \times 0.25 \mathrm{~mm} \times 0.25 \mu \mathrm{m})$ column (Agilent, Santa Clara, California, USA). The carrier gas was helium with a constant flow rate of $1.2 \mathrm{~mL} / \mathrm{min}$, and the injector temperature was set at $250{ }^{\circ} \mathrm{C}$. Injection was performed in splitless mode for $3 \mathrm{~min}$ and then operated at a split of $1 / 20$. The source and transfer line temperatures were set at $250{ }^{\circ} \mathrm{C}$. Ionization was performed by positive electronic impact (EI) at $70 \mathrm{eV}$, with argon being used for the second fragmentation.

\section{MH and 3 MHA quantifications by nano-liquid}

\section{chromatography-mass spectrometry (NanoLC-MS/MS)}

The concentrations of $3 \mathrm{MH}$ and $3 \mathrm{MHA}$ were determined using the method published by Roland et al. (2016), with $\mathrm{N}$-phenylmaleimide being added to $2 \mathrm{~mL}$ of wine sample for thiol derivatization. Derivatized thiols were extracted and purified using a Bond Elut Plexa cartridge from Agilent (Santa Clara, California, USA). After the samples were prepared, $4 \mu \mathrm{L}$ of the recovered derivatized thiols in $0.1 \%$ formic acid-containing water/acetonitrile (98/2) were injected on an HPLC-polymeric chip ProtID
(ZORBAX 300SB-C18, $40 \mathrm{~nL}, 5 \mu \mathrm{m}$ and $75 \mu \mathrm{m} * 43 \mu \mathrm{m}$, $5 \mu \mathrm{m})$. Compounds were chromatographically eluted using a nano-LC Agilent Series 1260 Infinity (Agilent, Santa Clara, California, USA) with a mobile phase of (A) water and (B) a mixture of ACN/TFE (90/10), both containing $0.1 \%(\mathrm{v} / \mathrm{v})$ formic acid. The HPLC-Chip cube interface was connected to an Agilent 6460 triple quadrupole mass spectrometer (Agilent Technologies, Waldbronn, Germany). The Agilent Mass Hunter ChemStation software (version B 04.01) was used for data acquisition and processing.

\section{Statistical analysis}

Statistical analyses were performed with $\mathrm{R}$ version 3.2.3 (R Development Core Team 2011).

\section{Box-Behnken experimental design}

We used the rsm library to implement the experimental design (Lenth 2009).

We used a Box-Behnken experimental design based on 16 fermentations, including 4 central points to evaluate the reproducibility in order to study the combined effects of sugar amount, lipid concentration and temperature on yeast metabolism during wine fermentation (Table 2). The impact of these factors on yeast central carbon metabolism was studied with a focus on acetic acid production, fermentation kinetics, cell population, cell viability and thiol liberation at the end of the fermentation.

Each studied variable had three coded factor levels: a low level, coded - 1; a high level, coded 1; and a midlevel, coded 0 .

The effect of the independent variables on a resultant value $\mathrm{Y}$ (for example, the acetic acid production) was modeled by a polynomial response surface:

\section{Table 2 Box-Behnken experimental design}

\begin{tabular}{llll}
\hline Experiments & $\begin{array}{l}\text { Lipid content } \\
(\% \mathbf{v} / \mathbf{v})\end{array}$ & Temperature $\left({ }^{\circ} \mathbf{C}\right)$ & Sugar $(\mathbf{g} / \mathbf{L})$ \\
\hline 1 & 0.0133 & 16 & 210 \\
2 & 0.0533 & 16 & 210 \\
3 & 0.0133 & 24 & 210 \\
4 & 0.0533 & 24 & 210 \\
5 & 0.0133 & 20 & 170 \\
6 & 0.0533 & 20 & 170 \\
7 & 0.0133 & 20 & 250 \\
8 & 0.0533 & 20 & 250 \\
9 & 0.0333 & 16 & 170 \\
10 & 0.0333 & 24 & 170 \\
11 & 0.0333 & 16 & 250 \\
12 & 0.0333 & 24 & 250 \\
$13^{a} ; 14^{a} ; 15^{a} ; 16^{a}$ & 0.0333 & 20 & 210 \\
\hline
\end{tabular}

a Central points of the experimental design were replicated 4 times 


$$
\begin{aligned}
Y= & \beta_{0}+\beta_{1} x_{1}+\beta_{2} x_{2}+\beta_{3} x_{3}+\beta_{12} x_{1} x_{2}+\beta_{13} x_{1} x_{3} \\
& +\beta_{23} x_{2} x_{3}+\beta_{11} x_{1}^{2}+\beta_{22} x_{2}^{2}+\beta_{33} x_{3}^{2}+\varepsilon
\end{aligned}
$$

where $\mathrm{x}_{1}, \mathrm{x}_{2}$, and $\mathrm{x}_{3}$ are the coded values of the studied variables (temperature, lipid initial concentration and sugar initial concentration), $\beta_{0}$ is the intercept term, $\beta_{\mathrm{i}}$ is the linear coefficient, $\beta_{\mathrm{ii}}$ is the quadratic coefficient, $\beta_{\mathrm{ij}}$ is the interaction coefficient and $\varepsilon$ is the error term. This model was represented by response surfaces.

\section{Mean comparisons}

To check the mean equality of the results obtained with the complete experimental design in natural grape must, we performed Student-Newman and Keuls (SNK) statistical tests using the library agricolae.

\section{Results}

The combined effects of sugar amount, lipid concentration and temperature on yeast metabolism during wine fermentation are shown in Table 3 (Additional file 1: Table S1).

\section{Effects of environmental conditions on the production of acetic acid and the main by-products of central carbon metabolism \\ Acetic acid}

The effects of environmental factors and conditions on the production of acetic acid by the 4 S. cerevisiae $\times S$. kudriavzevii hybrids are shown in Fig. 1. These factors have different impacts on acetic acid production. Both the lipid content (Tween80 and phytosterols) and sugar concentration have great impacts on the acetic acid production of the four strains. For strains Eg8_V2, Eg8_V3 and Eg8_V4, acetic acid production increases with the initial sugar concentration in a linear manner and decreases with the lipid content of the must. In addition, the lipid content has a positive quadratic impact on the acetic acid production yield of these strains. In the case of Eg8_V0, the acetic acid production yield is also affected by the sugar concentration and lipid content but only when they interact; that is, the acetic acid production yield increases when high initial sugar concentration is associated with low initial lipid concentration.

In addition to the lipid content, temperature also affects the acetic acid production yield of the different strains, with the exception of Eg8_V0: the production increases with the temperature in a quadratic manner. According to the response surface (Fig. 1), the optimal temperature to reduce acetic acid yield in the tested conditions is approximately $20^{\circ} \mathrm{C}$.

As expected, the two low acetic acid producing mutant strains Eg8_V2 and Eg8_V3 have a lower acetic acid yield than Eg8_V0 and Eg8_V4, independent of the environmental conditions. Moreover, the acetic acid production of Eg8_V0 seems less affected by variations of the environmental conditions, suggesting that this strain regulates acetic acid metabolism differently compared to the other hybrids studied.

\section{Glycerol, pyruvic acid, and succinic acid}

Temperature has the main impact on metabolite production yields for the four hybrids. Indeed, glycerol production increases linearly with temperature for all strains. Temperature also affects pyruvic acid yield in the same manner, except in the case of Eg8_V0. Moreover, regarding pyruvic acid production by Eg8_V0 and Eg8_V3, different response surface profiles are observed compared to the other strains due to temperature having a negative quadratic impact (Additional file 1: Fig. S1).

The two low acetic acid producing mutant strains, Eg8_ V2 and Eg8_V3, share similar responses to environmental factors. Temperature and sugar have a positive effect on glycerol yield as well as succinic acid production. Moreover, these two strains experience the same positive, linear effects of temperature and sugar concentration on succinic acid yield.

\section{Effects of environmental conditions on yeast growth, viability and fermentation rate}

According to Table 3, the addition of lipids has a positive impact on the fermentations performed by these hybrids. This is illustrated by an increase in cell population and viability at the end of the fermentation and a higher maximum fermentation rate $\left(\mathrm{V}_{\max }\right)$. Moreover, the lipid content has a negative quadratic effect on the cell viability.

Conversely, the viability and fermentation rate $\left(\mathrm{V}_{\max }\right)$ decrease when the initial concentration of sugar increases for all the strains except for Eg8_V4. Sugar concentration also impacts the populations of Eg8_V0 and Eg8_V2. Eg8_V0 and Eg8_V2 behave similarly in regards to the quadratic effect of the sugar concentration, which negatively impacts their viability and $\mathrm{V}_{\max }$. Finally, the viability of Eg8_V0 and Eg8_V2 is affected by a positive interaction between the lipid content and sugar concentration.

As expected, increasing the temperature to $24{ }^{\circ} \mathrm{C}$ strongly improves the fermentation rate $\left(\mathrm{V}_{\max }\right)$ for all the hybrids, even if they are cryophilic. This result is clearly illustrated by the response surface presented in Additional file 1: Fig. S2.

\section{Effects of environmental conditions on thiol liberation by Eg8_V2}

Since the storage and quantification of thiols present significant challenges, we decided to perform in depth 
Table 3 Combined effects of lipid concentration, temperature and sugar concentration on yeast growth, fermentation kinetics and carbon metabolism during wine fermentation

\begin{tabular}{|c|c|c|c|c|c|c|c|c|c|c|c|}
\hline \multirow{2}{*}{ Strain } & \multirow{2}{*}{ Response } & \multicolumn{3}{|c|}{ Linear } & \multicolumn{3}{|c|}{ Quadratic } & \multicolumn{3}{|c|}{ Interaction } & \multirow{2}{*}{$\mathbf{R}^{2}$} \\
\hline & & $\mathrm{LC}$ & $\mathrm{T}$ & $\mathrm{S}$ & $\mathrm{LC}$ & $\mathrm{T}$ & S & $\mathrm{LC}: \mathrm{T}$ & LC:S & $\mathrm{T}: \mathrm{S}$ & \\
\hline \multirow[t]{7}{*}{ Eg8_V0 } & Viability & + & - & - & - & & - & & + & - & 0.97 \\
\hline & Population & + & - & - & & & & - & & & 0.96 \\
\hline & $\mathrm{V}_{\max }$ & + & + & - & & + & - & & & & 0.99 \\
\hline & Acetic acid yield & & & & & & & & + & & 0.78 \\
\hline & Succinic acid yield & & & & & & & & & & 0.75 \\
\hline & Glycerol yield & + & + & - & & & + & & & & 0.97 \\
\hline & Pyruvic acid yield & & & & & - & & & & & 0.75 \\
\hline \multirow[t]{7}{*}{ Eg8_V2 } & Viability & + & - & - & - & & - & + & & & 0.96 \\
\hline & Population & + & & - & & & & & & & 0.91 \\
\hline & $\mathrm{V}_{\max }$ & + & + & - & & + & - & & & & 0.99 \\
\hline & Acetic acid yield & - & & + & + & + & & & & & 0.92 \\
\hline & Succinic acid yield & + & + & & & & & & & & 0.83 \\
\hline & Glycerol yield & & + & & & & & & & & 0.62 \\
\hline & Pyruvic acid yield & + & + & - & & & & & & & 0.89 \\
\hline \multirow[t]{7}{*}{ Eg8_V3 } & Viability & + & & - & - & & & & + & & 0.97 \\
\hline & Population & + & & & & & & & & & 0.81 \\
\hline & $\mathrm{V}_{\max }$ & + & + & - & - & + & + & & & & 0.99 \\
\hline & Acetic acid yield & - & & + & + & + & & & & & 0.97 \\
\hline & Succinic acid yield & & + & + & & & & & & + & 0.95 \\
\hline & Glycerol yield & & + & & & & & & & + & 0.96 \\
\hline & Pyruvic acid yield & & + & - & - & - & & & & & 0.96 \\
\hline \multirow[t]{7}{*}{ Eg8_V4 } & Viability & + & & & - & & & & & & 0.84 \\
\hline & Population & + & & & & & & & & & 0.76 \\
\hline & $\mathrm{V}_{\max }$ & + & + & & & & & & & & 0.99 \\
\hline & Acetic acid yield & - & + & + & + & + & & & & & 0.91 \\
\hline & Succinic acid yield & & & & & & & & - & & 0.72 \\
\hline & Glycerol yield & & + & & + & & + & & - & & 0.91 \\
\hline & Pyruvic acid yield & & + & & & & & & & & 0.79 \\
\hline
\end{tabular}

LC lipid content, $T$ temperature, $S$ sugar

Red: $p<0.001$, orange: $p<0.01$, yellow: $p<0.05$, white: not-significant. (+): positive effect, $(-)$ : negative effect

analysis of one single strain. The strain Eg8_V2, which produces low acetic acid levels, a desirable property for winemaking, was selected for this study.

In synthetic media, we found a positive linear effect of the lipid content on 3MH liberation (Fig. 2). As thiols are volatile compounds present at low concentrations in wine and are difficult to store and quantify, we decided to confirm this effect and further explore the effects of other environmental factors on thiol release using a complete experimental design with fermentations in triplicate for 

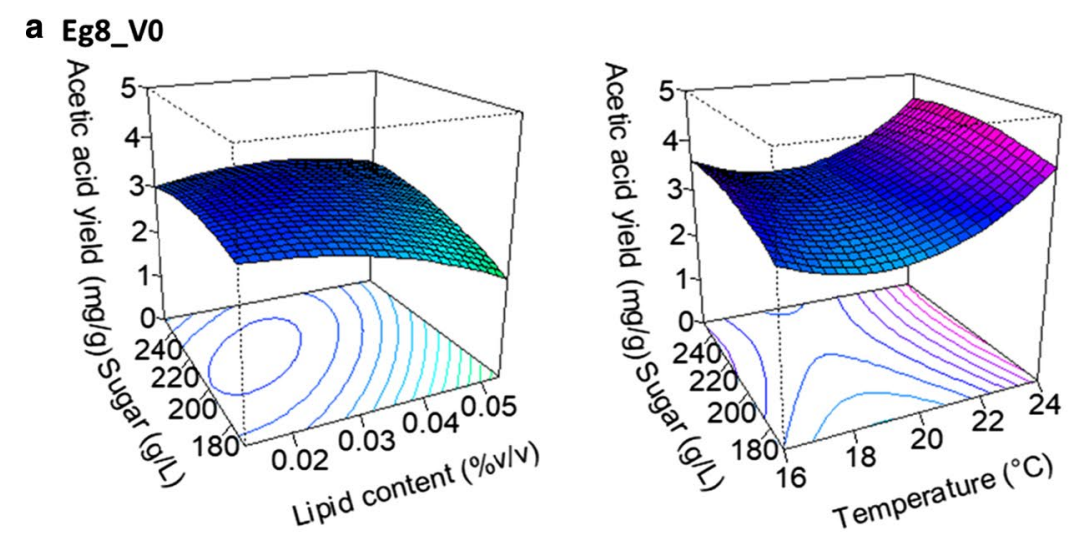

b Eg8_V2
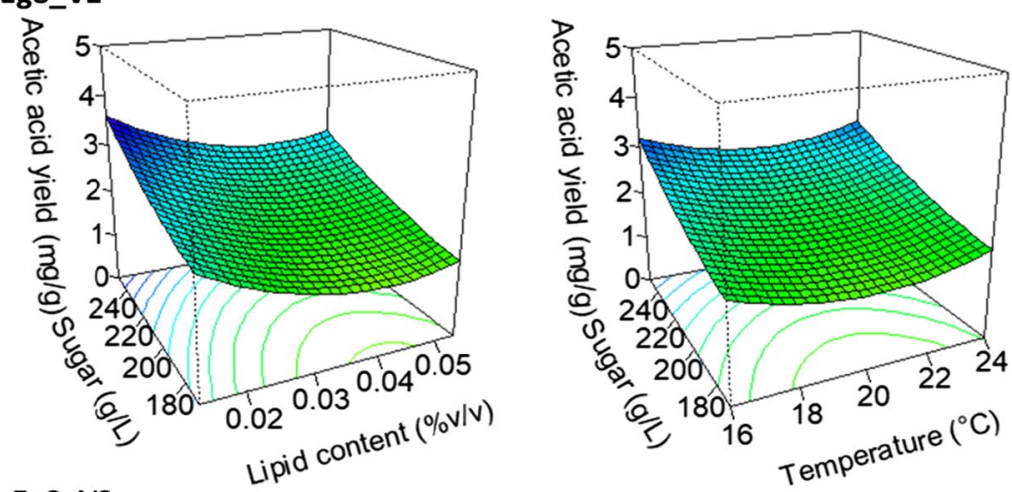

C Eg8_V3
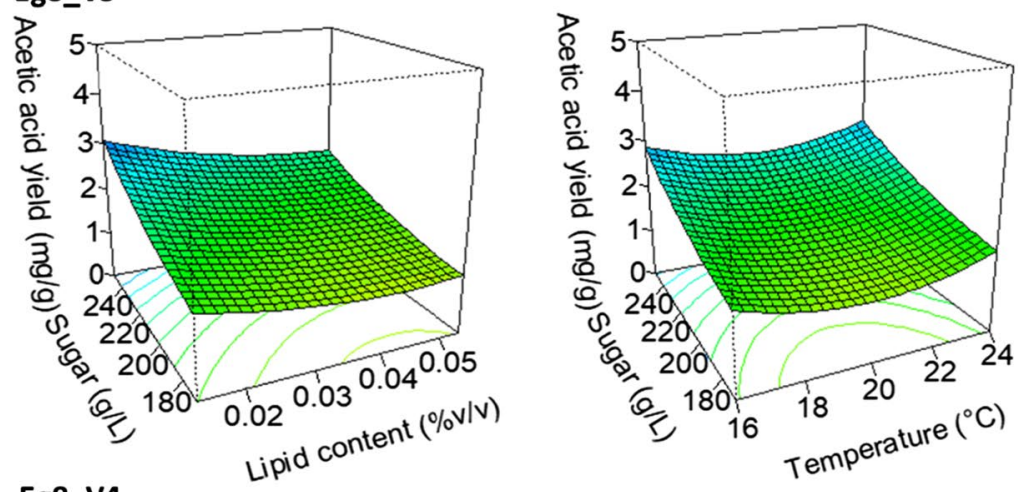

d Eg8_V4
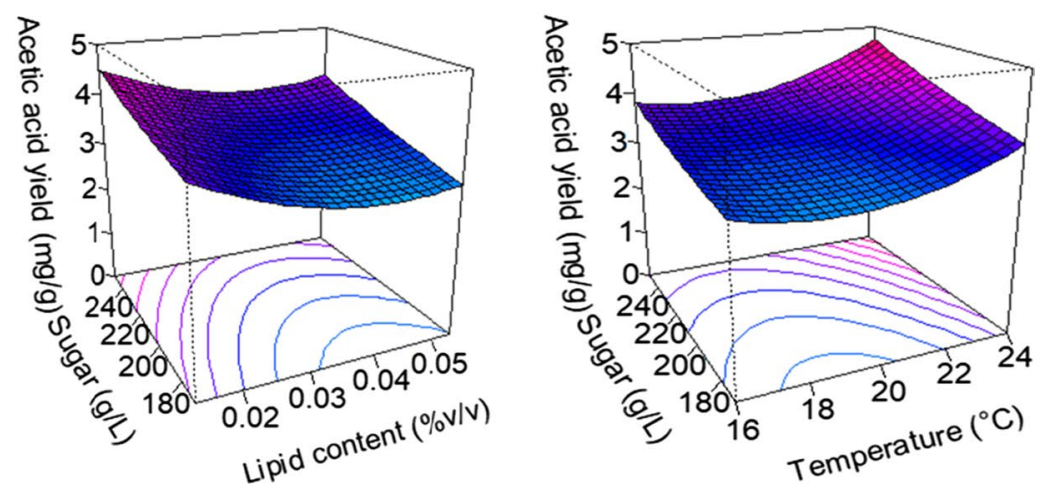

Fig. 1 Evolution of acetic acid yield of S. cerevisiae X S. kudriavzevii hybrids Eg8_V0 (a), Eg8_V2 (b), Eg8_V3 (c) and Eg8_V4 (d) under different environmental conditions 

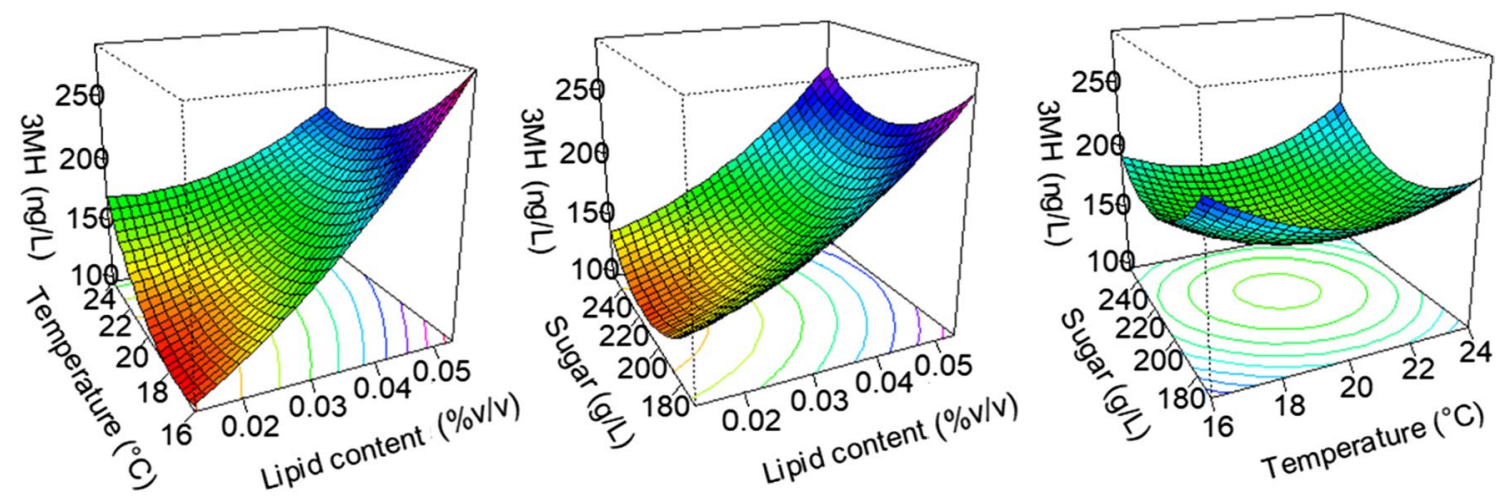

Fig. 2 Effect of lipid content, sugar concentration and temperature on the liberation of 3MH by Eg8_V2

all conditions. Moreover, all thiol precursors have not yet been discovered. Subileau et al. (2008) demonstrated that Cys-3MH was only responsible for $3-7 \%$ of the total $3 \mathrm{MH}$ in wine. Among these uncharacterized precursors, glutathionylated precursors are very likely to have a significant role. Indeed, Subileau et al. (2008) compared the Cys-3MH conversion yields obtained by Howell et al. (2004), Dubourdieu et al. (2006) and Masneuf Pomerede et al. (2006) and showed that the Cys-3MH conversion yield is higher in grape musts (up to 10\%) than in synthetic media (below 1\%). Therefore, our results obtained in a synthetic media may not mimic the reality. This prompted us to perform a complementary study in a natural grape must in order to take into account the full set of thiol precursors present in this must.

\section{Experimental validation of the effect of the lipid content of grape must on thiol release and acetic acid production} We performed our complementary study using a Sauvignon Blanc grape must. As Twen 80 contains fatty acids, the lipid effect observed in synthetic must can be due to phytosterols, fatty acids or both. To dissociate these effects, we tested the effect of Tween 80 separately from that of phytosterols. We also tested the effects of temperature on the thiols released from grape precursors under these conditions. At the same time, we wanted to confirm the effects of these factors on acetic acid production. The results are presented in Figs. 3 and 4 (Additional file 1: Tables S2 and S3).

\section{Impact of the lipid content and fermentation temperature on thiol release in natural grape must}

Figure $3 \mathrm{a}$, b clearly show that an increase in the lipid content of grape must, provided as either Tween $80+$ phytosterols or Tween 80 alone, result in an increase in the amount of 3MH and 4MMP released by Eg8_V2 during alcoholic fermentation. Conversely, 3MHA is negatively impacted by the initial lipid concentration (Fig. 3c). As a result, the $3 \mathrm{MH} / 3 \mathrm{MHA}$ ratio is multiplied by 3 between the modalities containing the lowest and highest lipid contents, independent of the fermentation temperature (Fig. 3d). We can hypothesize that lipid addition leads to a decrease in the acetylation of $3 \mathrm{MH}$ into 3MHA since the sum of the $3 \mathrm{MH}$ and 3MHA does not vary with the lipid concentration (Fig. 3e).

The release of $3 \mathrm{MH}$ and $4 \mathrm{MMP}$ is not affected by the fermentation temperature. In contrast, the 3MHA concentration decreases when temperature increases. Depending on the lipid content, the concentration of 3MHA decreases by $20-35 \%$ when the temperature increases from 16 to $24{ }^{\circ} \mathrm{C}$ (Fig. 3c). The 3MH/3MHA ratio increases with temperature (Fig. $3 \mathrm{~d}$ ).

\section{Impact of the lipid content and fermentation temperature on acetic acid production in natural grape must}

The effects of lipids on acetic acid production was studied in the grape must used for the evaluation of thiols and in that same grape must after clarification and enrichment to reach a sugar content of $240 \mathrm{~g} / \mathrm{L}$. Small differences in acetic acid concentration (between 0.11 and $0.17 \mathrm{~g} / \mathrm{L}$ ) were found in the untreated grape must (Additional file 1: Table S2), very likely because of its high turbidity (140 NTU). In contrast, a marked effect of lipids was observed in the clarified grape must; the acetic acid production decreased with higher initial concentrations of lipids. This effect was also observed when the lipid source was Tween 80 alone. The impact was stronger when lipids were added in amounts between 0.0133 and $0.0333 \% \mathrm{v} / \mathrm{v}$ : acetic acid production dropped from 0.3 to $0.2 \mathrm{~g} / \mathrm{L}$ (Fig. 4a and Additional file 1: Table S3). Moreover, this acetic acid production decrease accompanies an increase in succinic and pyruvic acids (Fig. 4b, c). 


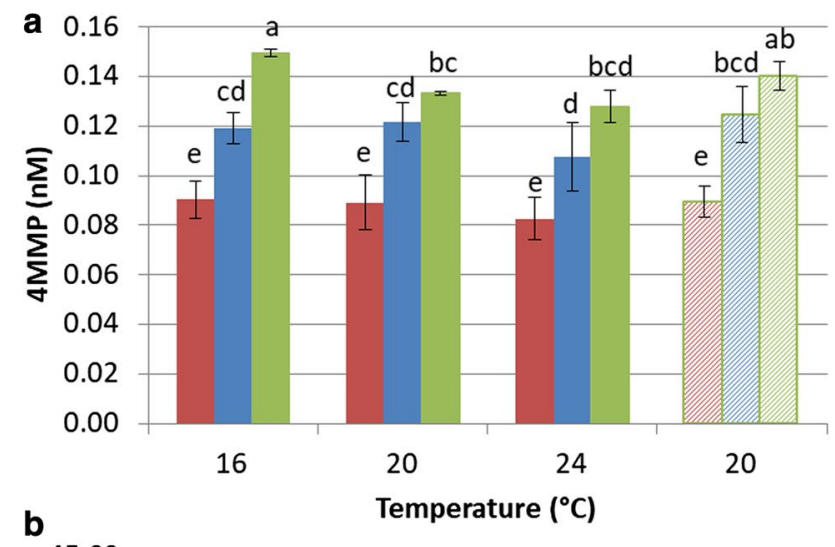

b

Temperature $\left({ }^{\circ} \mathrm{C}\right)$

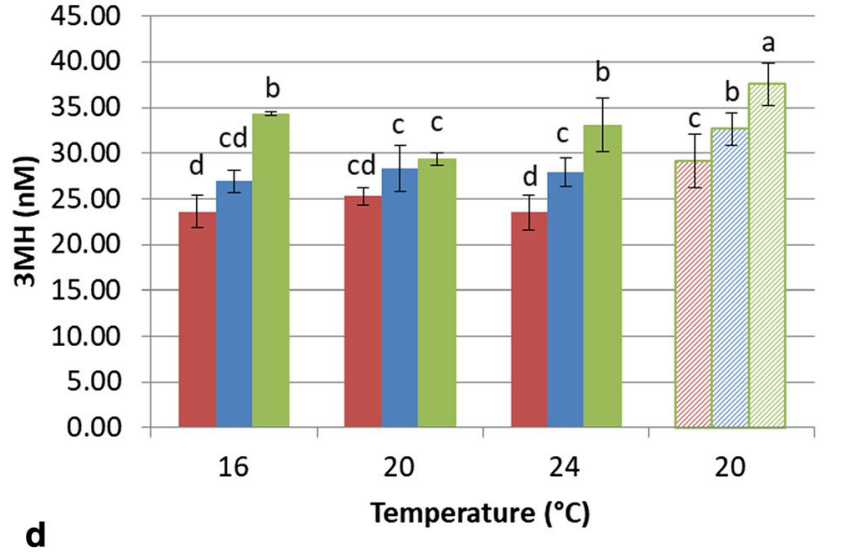

C
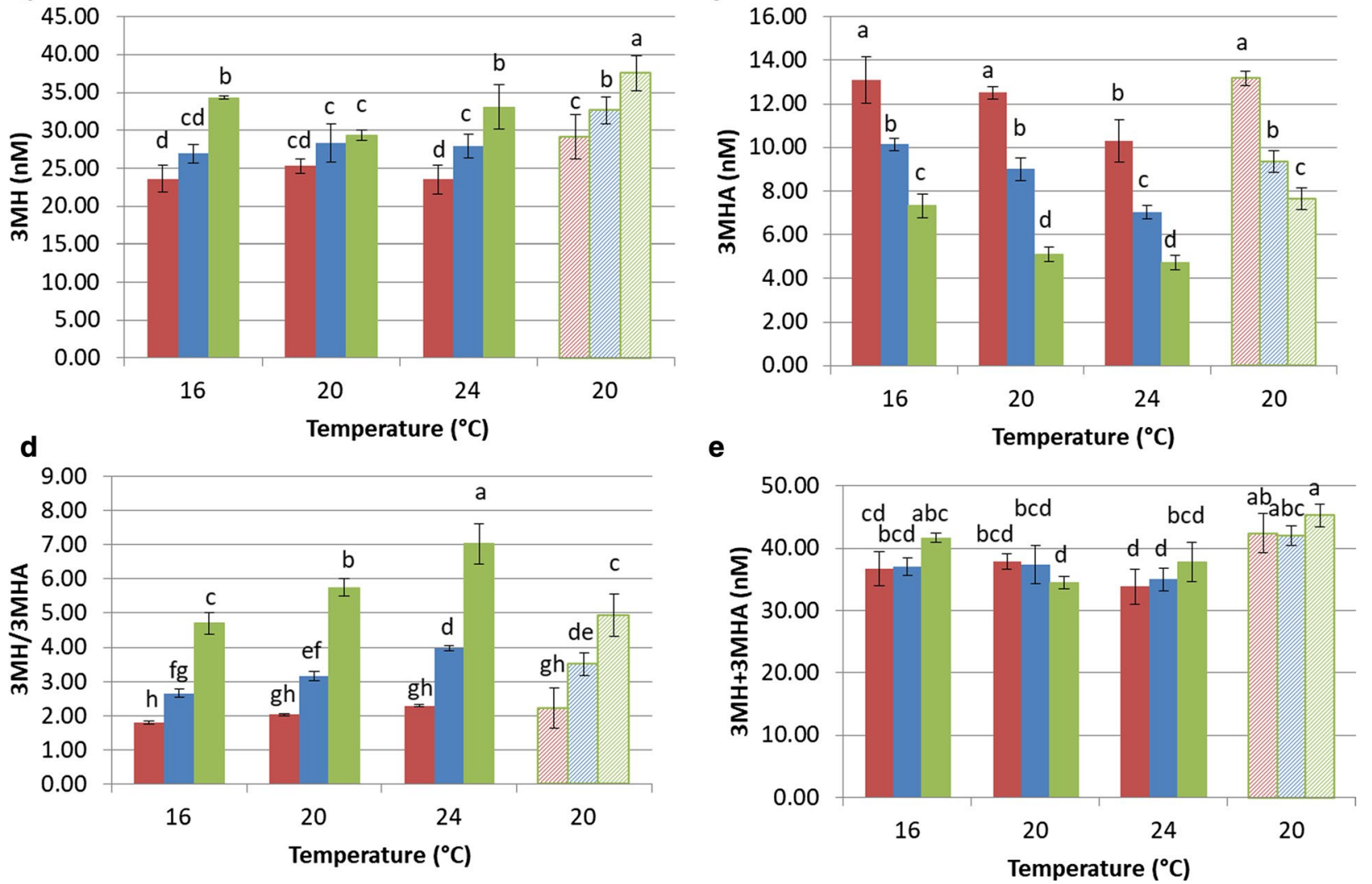

Fig. 3 Impact of the initial concentration and nature of the lipid content and of the temperature on the production of $4 \mathrm{MMP}(\mathbf{a}), 3 \mathrm{MH}(\mathbf{b})$ and $3 \mathrm{MHA}$ (c) and on the 3MH/3MHA ratio (d) and 3MH+3MHA sum (e) during alcoholic fermentation by Eg8_V2 in Sauvignon Blanc du Gers 2017. Lipid content: red $=0.0133 \% \mathrm{v} / \mathrm{v}$; blue $=0.0333 \% \mathrm{v} / \mathrm{v}$; green $=0.0533 \% \mathrm{v} / \mathrm{v}$; filled bar $=$ phytosterols + Tween 80 ; hatched bar $=$ Tween 80 only; letters above bars $=$ groups generated with SNK test

\section{Discussion}

Eg8 is a $S$. cerevisiae $\times$ S. kudriavzevii natural hybrid mainly used in white wine fermentation because of its cryophilic character and its strong ability to release varietal thiols. However, Eg8 has been described as a high acetic acid producer. The aim of this work was to identify environmental conditions that could minimize acetic acid production while maintaining a high thiol concentration at the end of the fermentation. We focused our study on the impact of the initial sugar and lipid concentrations and temperature. To explore the effects of these three factors, we used a Box-Behnken experimental design, which enabled us to build a model describing the effect of each factor and their interactions.

We showed that acetic acid production by the hybrids decreases when the medium is supplemented with 

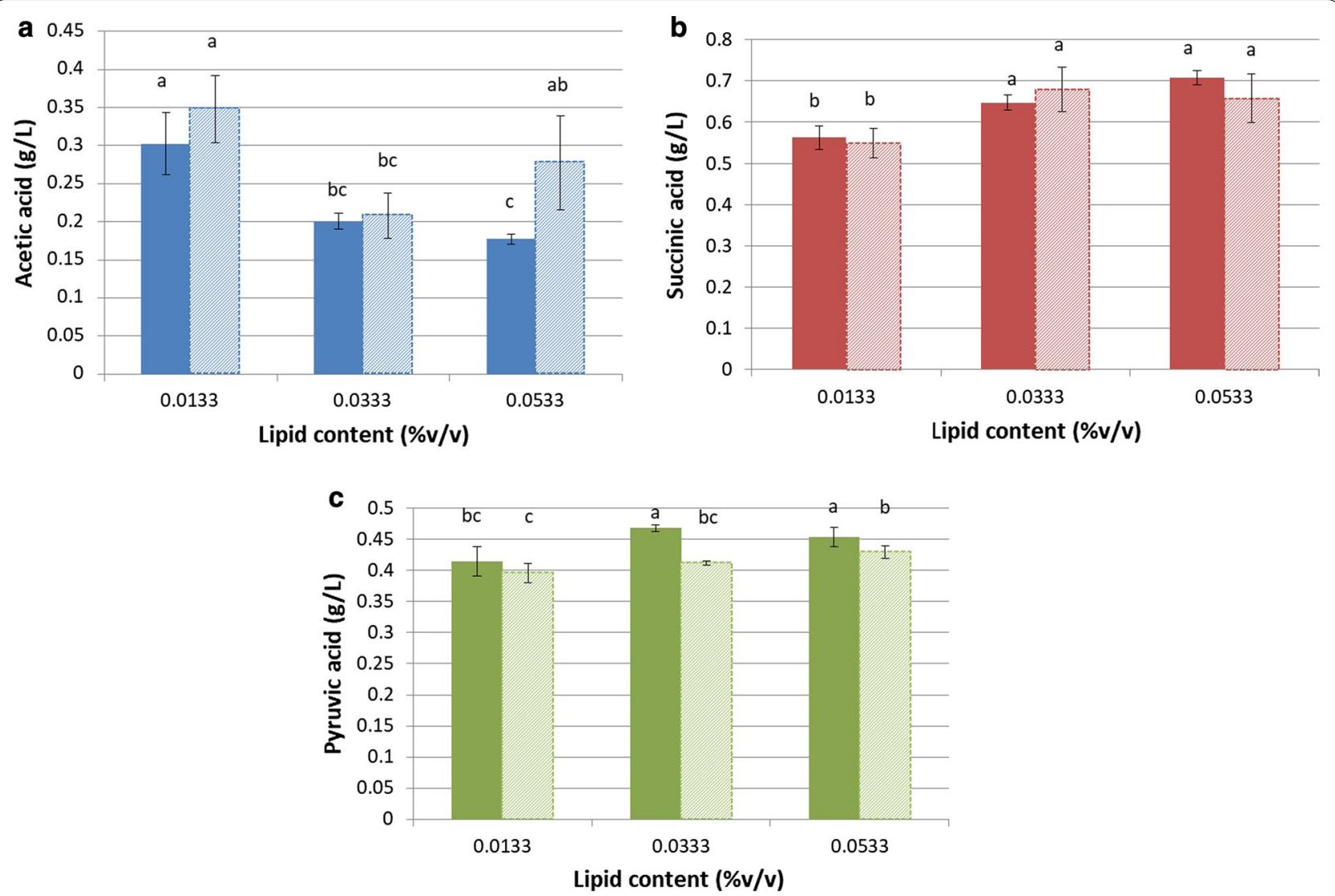

Fig. 4 Impact of the initial concentration and nature of the lipid content on the production of acetic acid (a), succinic acid (b) and pyruvic acid (c) during alcoholic fermentation by Eg8_V2 at $20^{\circ} \mathrm{C}$ in Sauvignon Blanc du Gers 2017 clarified until 20 NTU and chaptalized at $240 \mathrm{~g} / \mathrm{L}$ sugar. Filled $\mathrm{bar}=$ phytosterols + Tween80; hatched bar =Tween80 only; letters above bars = groups generated with SNK test

lipids, in both a synthetic must and a highly clarified grape must. A negative effect of lipid addition on the acetic acid production by S. cerevisiae had already been reported in several studies (Belviso et al. 2004; Delfini et al. 1992; Landolfo et al. 2010; Ochando et al. 2016; Rollero et al. 2015; Thurston et al. 1981; Varela et al. 2012). The main hypothesis to explain this relation between lipids and acetic acid production is that in anaerobiosis, when yeast is confronted with a deprivation of lipids in the medium, it synthetizes its own lipids from cytosolic acetyl-CoA (Parks and Adams 1978). Since the PDH bypass is the main metabolic pathway leading to cytosolic acetyl-CoA synthesis (Flikweert et al. 1996; Van Der Berg and Steensma 1995), it could be hypothesized that the lack of fatty acids and sterols in the medium leads to an increased pyruvic acid flux through the PDH bypass in order to produce more cytosolic acetyl-CoA. Since acetic acid is an intermediate of this pathway, its concentration increases when yeast faces a lipid deficiency in anaerobiosis. We also found that the initial lipid concentration influences the fermentation rate, yeast population and viability in a positive way for all the hybrids tested, as described previously for S. cerevisiae (Casalta et al. 2013; Houtman and Du Plessis 1981; Luparia et al. 2004; Ochando et al. 2016). Since clarification leads to a loss of sterols and fatty acids from the grape must (Cocito and Delfini 1997), this step of the winemaking process has to be controlled to avoid stuck fermentation and excessive production of acetic acid (Houtman and Du Plessis 1981; Delfini and Costa 1993).

In the case of Eg8_V2, the initial lipid concentration decrease also leads to a decrease in pyruvic acid and succinic acid concentrations in both the synthetic and natural grape musts. During wine fermentation, Krebs cycle enzymes are subjected to catabolite repression due to the high glucose concentration (Gancedo 2008), and the Krebs cycle functions as two branches with succinic acid as a final product (Gombert et al. 2001; Camarasa et al. 2003). The decrease in succinic acid concentration, coupled with higher acetic acid production, is consistent with a redistribution of the metabolic flux of central carbon metabolism from the Krebs cycle to the PDH bypass 
under conditions of lipid limitation. This supports the hypothesis that yeast use the cytosolic acetyl-CoA produced through the PDH bypass to produce their own fatty acids in order to counter lipid deficiencies.

Acetic acid production of Eg8_V2, Eg8_V3, and Eg8_ $\mathrm{V} 4$ increases in a linear manner with the initial sugar concentration. This confirms results previously obtained for 8 S. cerevisiae strains in a natural grape must by Ferreira et al. (2006) and is very likely associated with a higher expression of ALD4 and ALD6 (Erasmus et al. 2003; Saint-Prix et al. 2004). Indeed, these two genes from the ACDH family are involved in the conversion of acetaldehyde into acetic acid in the PDH bypass (Remize et al. 2000). This might be related to osmotic stress impacting the pentose phosphate pathway (PPP), whose oxidative pathway is a major source of NADPH for the yeast. The acetaldehyde oxidation into acetic acid by ALD6 leads to NADPH regeneration and compensates for the PPP imbalance (Erasmus et al. 2003; Erasmus and van Vuuren 2009).

We found that the environmental effects on acetic acid production are similar for the hybrids, although the magnitude of these effects was strain specific. As expected, the two low acetic acid mutants Eg8_V2 and Eg8_V3 have a lower acetic acid production than the other strains under the same environmental conditions. Indeed, Eg8 V2 and Eg8_V3 have been obtained by UV mutagenesis from other strains from the Eg8 family, and selected for their low acetic acid production. In the present study, the production of acetic acid of Eg8_V2 and Eg8_V3 never exceeded $0.7 \mathrm{~g} / \mathrm{L}$ (Ribéreau-Gayon et al. 2006), described as the concentration before organoleptic quality degradation of the wine occurs. Our study emphasizes the importance of strain choice, in addition to environmental conditions. To optimize the wine fermentation, these two parameters should be considered.

Using Eg8_V2, we also studied the influence of environmental conditions on the final concentration of thiols in wines obtained by fermentations of synthetic and natural grape musts. We found that lipid addition (phytosterols + Tween 80 or Tween 80 alone) leads to an increase in the final concentration of $3 \mathrm{MH}$ in both cases (Figs. 2, $3 b)$. Moreover, in natural grape must, we also found that the higher the initial lipid concentration is, the higher the final 4MMP concentration (Fig. 3a). Pinu et al. (2014) previously showed that adding linolenic acid (four times the initial concentration) to a must leads to a doubling of the $4 \mathrm{MMP}$ content and a $17 \%$ increase in the $3 \mathrm{MH}$ content. The increase in the amounts of $3 \mathrm{MH}$ and $4 \mathrm{MMP}$ released as the lipid concentration is increased could be explained by the antioxidant properties of lipid nutrients (Landolfo et al. 2010). Indeed, it has been demonstrated that adding antioxidant molecules $\left(120 \mathrm{mg} / \mathrm{kg} \mathrm{SO}_{2}\right)$ to the grape must leads to an increase in final thiol concentrations (Saharan et al. 2010).

Moreover, we observed in this study a decrease in 3MHA production when the lipid concentrations were increased. However, we showed that the global production of $3 \mathrm{MH}(3 \mathrm{MH}+3 \mathrm{MHA})$ was not impacted by the lipid concentration (Fig. 3e). This suggests an increase in the conversion of $3 \mathrm{MH}$ into $3 \mathrm{MHA}$ when the lipid content is low, leading to a decrease in the $3 \mathrm{MH} / 3 \mathrm{MHA}$ ratio. For example, at $24{ }^{\circ} \mathrm{C}$, the $3 \mathrm{MH} / 3 \mathrm{MHA}$ ratio drops from 7.03 to 2.29 when the lipid content decreases from 0.0533 to $0.0133 \% \mathrm{v} / \mathrm{v}$ (Fig. $3 \mathrm{~d}$ ). One potential reason is that the conversion of $3 \mathrm{MH}$ into $3 \mathrm{MHA}$ is catalyzed by an alcohol acetyltransferase encoded by ATF1 (Verstrepen et al. 2003), whose expression is repressed by unsaturated fatty acids (Fujii et al. 1997). Moreover, 3MHA is the product of acetylation between $3 \mathrm{MH}$ and acetyl-CoA (Swiegers and Pretorius 2007). We previously hypothesized that lipids limitation leads to increased production of cytosolic acetyl-CoA, which is required for fatty acid production in anaerobiosis. A greater availability of acetyl-CoA could also explain the higher $3 \mathrm{MH}$ acetylation when lipid concentration decreases.

The reduced acetylation of $3 \mathrm{MH}$, along with the high concentrations of lipids observed in our study (Fig. 3d, e), results in the modification of the aromatic profile from one with a passion fruit aroma brought about by the 3MHA to one with a citrus aroma brought by the $3 \mathrm{MH}$, which could be interesting for winemakers.

To conclude, we demonstrated that the lipid content of the must is critical for wine fermentations performed by S. cerevisiae $\times$ S. kudriavzevii hybrid strains from the Eg8 cluster. Indeed, when Eg8 hybrids undergo lipid deprivation, their acetic acid production increases and their liberation of thiols is modified, leading to more passion fruit aromas and less box tree and citrus notes (the 4MMP released is lower and the acetylation of $3 \mathrm{MH}$ increases). Therefore, as the clarification of the must is critical for the lipid content (Cocito and Delfini 1997), a must clarification strategy needs to be chosen according to the aromatic profile that the winemaker is searching for while minimizing the risk of excessive acetic acid production. Further improvement of these strains needs to be performed in order to obtain new starters that can maximize 3MHA production without the risk of excessive acetic acid production. 


\section{Additional file}

Additional file 1. Additional figures and tables.

\begin{abstract}
Abbreviations
ACDH: acetaldehyde dehydrogenase; Cys: cysteine; El: electronic impact; GC: gas chromotography; Glu: glutathione; MS: mass spectrometry; NanoLC: nano liquid chromatography; NTU: nephelometric turbidity unit; PDH: pyruvate dehydrogenase; PI: propidium iodide; PPP: pentose phosphate pathway; S. cerevisiae: Saccharomyces cerevisiae; SIDA: stable isotope dilution assay; S. kudriavzevii: Saccharomyces kudriavzevii; SM: synthetic must; SNK: StudentNewman and Keuls; SPME: solid-phase microextraction; $V_{\max }$ : maximum fermentation rate; v/v: volume/volume; w/v: weight/volume; YAN: yeast available nitrogen; YPD: yeast extract peptone dextrose; 3MH: 3-mercaptohexan-1-ol; 3MHA: 3-mercaptohexyl acetate; 4MMP: 4-methyl-4-mercaptopentan-2-one.
\end{abstract}

\section{Authors' contributions}

$\mathrm{SD}, J \mathrm{LL}$ and $\mathrm{AD}$ conceived and designed the experiments. AD performed the experiments and analysed the data. PR supervised the thiol assays. SD, $J L L, A J$ provided inputs in data interpretation. AD wrote the manuscript and SD and JLL polished the manuscript. All authors read and approved the final manuscript.

\section{Author details}

${ }^{1}$ Lallemand SAS, 31700 Blagnac, France. ${ }^{2}$ SPO, Univ Montpellier, INRA, Montpellier SupAgro, Montpellier, France.

\section{Acknowledgements}

We thank Luc Dellac and Nicolas Bouvier for helping during thiol quantification and Christian Picou and Marc Perez for their assistance during robotassisted fermentations.

\section{Competing interests}

The authors declare that they have no competing interests.

\section{Availability of data and materials}

The datasets supporting the conclusions of this article are included within the article and its additional files.

\section{Consent for publication}

Not applicable.

\section{Ethics approval and consent to participate}

Not applicable.

\section{Funding}

Not applicable/no funding was received for this study.

\section{Publisher's Note}

Springer Nature remains neutral with regard to jurisdictional claims in published maps and institutional affiliations.

Received: 25 July 2018 Accepted: 30 July 2018

Published online: 10 August 2018

\section{References}

Belloch C, Orlic S, Barrio E, Querol A (2008) Fermentative stress adaptation of hybrids within the Saccharomyces sensu stricto complex. Int J Food Microbiol 122:188-195. https://doi.org/10.1016/j.ijfoodmicro.2007.11.083

Beltran G, Novo M, Guillamón JM, Mas A, Rozès N (2008) Effect of fermentation temperature and culture media on the yeast lipid composition and wine volatile compounds. Int J Food Microbiol 121:169-177. https://doi. org/10.1016/j.jijfoodmicro.2007.11.030

Belviso S, Bardi L, Bartolini AB, Marzona M (2004) Lipid nutrition of Saccharomyces cerevisiae in winemaking. Can J Microbiol 50:669-674. https://doi. org/10.1139/w04-051
Bely M, Sablayrolles J-M, Barre P (1990) Automatic detection of assimilable nitrogen deficiencies during alcoholic fermentation in oenological conditions. J Ferment Bioeng 70:246-252

Box GEP, Behnken DW (1960) Some new three level designs for the study of quantitative variables. Technometrics 2:455-475. https://doi. org/10.1080/00401706.1960.10489912

Camarasa C, Grivet J-P, Dequin S (2003) Investigation by 13C-NMR and tricarboxylic acid (TCA) deletion mutant analysis of pathways for succinate formation in Saccharomyces cerevisiae during anaerobic fermentation. Microbiology 149:2669-2678. https://doi.org/10.1099/mic.0.26007-0

Casalta E, Cervi MF, Salmon JM, Sablayrolles JM (2013) White wine fermentation: interaction of assimilable nitrogen and grape solids. Aust J Grape Wine Res 19:47-52. https://doi.org/10.1111/j.1755-0238.2012.00205.x

Cocito C, Delfini C (1997) Experiments for developing selective clarification techniques: sterol and fatty acid loss from grape must related to clarification technique. J Wine Res 8:187-197. https://doi.org/10.1080/09571 269708718119

Dagan L (2006) Potentiel aromatique des raisins de Vitis vinifera L. Cv. Petit Manseng et Gros Manseng. Contribution à l'arôme des vins de pays Côtes de Gascogne. http://www.theses.fr. Accessed 25 Apr 2018

Dagan L, Reillon F, Roland A, Schneider R (2014) Development of a routine analysis of 4-mercapto-4-methylpentan-2-one in wine by stable isotope dilution assay and mass tandem spectrometry. Anal Chim Acta 821:48-53. https://doi.org/10.1016/j.aca.2014.03.004

Delfini C, Costa A (1993) Effects of the grape must lees and insoluble materials on the alcoholic fermentation rate and the production of acetic acid, pyruvic acid, and acetaldehyde. Am J Enol Vitic 44:86-92

Delfini C, Pessione E, Moruno EG, Giunta C (1992) Localization of volatile acidity reducing factors in grape. J Ind Microbiol 11:19-22. https://doi. org/10.1007/BF01583727

Dubourdieu D, Tominaga T, Masneuf I, Peyrot des Gachons C, Murat ML (2006) The role of yeasts in grape flavor development during fermentation: the example of Sauvignon blanc. Am J Enol Vitic 57:81-88

Erasmus DJ, van Vuuren HJJ (2009) Genetic basis for osmosensitivity and genetic instability of the wine yeast Saccharomyces cerevisiae VIN7. Am J Enol Vitic 60:145-154

Erasmus DJ, van der Merwe GK, van Vuuren HJJ (2003) Genome-wide expression analyses: metabolic adaptation of Saccharomyces cerevisiae to high sugar stress. FEMS Yeast Res 3:375-399

Erny C, Raoult P, Alais A, Butterlin G, Delobel P, Matei-Radoi F, Casaregola S, Legras JL (2012) Ecological success of a group of Saccharomyces cerevisiae/Saccharomyces kudriavzevii hybrids in the northern european wine-making environment. Appl Environ Microbiol 78:3256-3265. https ://doi.org/10.1128/AEM.06752-11

Ferreira J, DU Toit M, DU Toit WJ (2006) The effects of copper and high sugar concentrations on growth, fermentation efficiency and volatile acidity production of different commercial wine yeast strains. Aust J Grape Wine Res 12:50-56. https://doi.org/10.1111/j.1755-0238.2006.tb00043.x

Flikweert MT, Van Der Zanden L, Janssen WM, Steensma HY, Van Dijken JP, Pronk JT (1996) Pyruvate decarboxylase: an indispensable enzyme for growth of Saccharomyces cerevisiae on glucose. Yeast 12:247-257. https ://doi.org/10.1002/(SICI)1097-0061(19960315)12:3\%3c247:AID-YEA91 $1 \% 3 e 3.0 . \mathrm{CO}^{2}-1$

Fujii T, Kobayashi O, Yoshimoto H, Furukawa S, Tamai Y (1997) Effect of aeration and unsaturated fatty acids on expression of the Saccharomyces cerevisiae alcohol acetyltransferase gene. Appl Environ Microbiol 63:910-915

Gancedo JM (2008) The early steps of glucose signalling in yeast. FEMS Microbiol Rev 32:673-704. https://doi.org/10.1111/j.1574-6976.2008.00117.x

Gombert AK, Moreira dos Santos M, Christensen B, Nielsen J (2001) Network identification and flux quantification in the central metabolism of Saccharomyces cerevisiae under different conditions of glucose repression. J Bacteriol 183:1441-1451. https://doi.org/10.1128/JB.183.4.1441-1451.2001

Holt S, Cordente AG, Williams SJ, Capone DL, Jitjaroen W, Menz IR, Curtin C, Anderson PA (2011) Engineering Saccharomyces cerevisiae to release 3-mercaptohexan-1-ol during fermentation through overexpression of an S. cerevisiae Gene, STR3, for improvement of wine aroma. Appl Environ Microbiol 77:3626-3632. https://doi.org/10.1128/AEM.03009-10

Holzer H, Goedde HW (1957) Two paths from pyruvate to acetyl coenzyme A in yeast. Biochem Ztschr 329:175-191

Houtman AC, Du Plessis CS (1981) The effect of juice clarity and several conditions promoting yeast growth on fermentation rate, the production of 
aroma components and wine quality. S Afr J Enol Vitic 2:71-81. https:// doi.org/10.21548/2-2-2399

Howell KS, Swiegers JH, Elsey GM, Siebert TE, Bartowsky EJ, Fleet GH, Pretorius IS, Barros Lopes MA (2004) Variation in 4-mercapto-4-methyl-pentan2-one release by Saccharomyces cerevisiae commercial wine strains. FEMS Microbiol Lett 240:125-129. https://doi.org/10.1016/j.femsle.2004.09.022

Howell KS, Klein M, Swiegers JH, Hayasaka Y, Elsey GM, Fleet GH, Høj PB, Pretorius IS, de Barros Lopes MA (2005) Genetic determinants of volatile-thiol release by Saccharomyces cerevisiae during wine fermentation. Appl Environ Microbiol 71:5420-5426. https://doi.org/10.1128/ AEM.71.9.5420-5426.2005

Landolfo S, Zara G, Zara S, Budroni M, Ciani M, Mannazzu I (2010) Oleic acid and ergosterol supplementation mitigates oxidative stress in wine strains of Saccharomyces cerevisiae. Int J Food Microbiol 141:229-235. https://doi. org/10.1016/J.IJFOODMICRO.2010.05.020

Legras J-L, Merdinoglu D, Cornuet J-M, Karst F (2007) Bread, beer and wine: Saccharomyces cerevisiae diversity reflects human history. Mol Ecol 16:2091-2102. https://doi.org/10.1111/j.1365-294X.2007.03266.x

Legras J-L, Galeote V, Bigey F, Camarasa C, Marsit S, Nidelet T, Sanchez I, Couloux A, Guy J, Franco-Duarte R, Marina M-H, Gabaldon T, Schuller D, Sampaio JP, Dequin S (2018) Adaptation of S. cerevisiae to fermented food environments reveals remarkable genome plasticity and the footprints of domestication. Mol Biol Evol 35:1712-1727. https://doi.org/10.1093/ molbev/msy066

Lenth R (2009) Response-Surface methods in R, using rsm. J Stat Softw 32:1-17

Liti G, Carter DM, Moses AM, Warringer J, Parts L, James SA, Davey RP, Roberts IN, Burt A, Koufopanou V, Tsai IJ, Bergman CM, Bensasson D, O'Kelly MJT, van Oudenaarden A, Barton DBH, Bailes E, Nguyen AN, Jones M, Quail MA, Goodhead I, Sims S, Smith F, Blomberg A, Durbin R, Louis EJ (2009) Population genomics of domestic and wild yeasts. Nature 458:337-341. https://doi.org/10.1038/nature07743

Luparia V, Soubeyrand V, Berges T, Julien A, Salmon J-M (2004) Assimilation of grape phytosterols by Saccharomyces cerevisiae and their impact on enological fermentations. Appl Microbiol Biotechnol 65:25-32. https:// doi.org/10.1007/s00253-003-1549-3

Marsit S, Dequin S (2015) Diversity and adaptive evolution of Saccharomyces wine yeast: a review. FEMS Yeast Res 15:1-12. https://doi.org/10.1093/ femsyr/fov067

Masneuf Pomerede I, Mansour C, Murat M-L, Tominaga T, Dubourdieu D, Masneuf-Pomarède I, Mansour C, Murat M-L, Tominaga T, Dubourdieu D (2006) Influence of fermentation temperature on volatile thiols concentrations in Sauvignon blanc wines. Int J Food Microbiol 108:385-390. https://doi.org/10.1016/j.ijfoodmicro.2006.01.001

Monk PR, Cowley PJ (1984) Effect of nicotinic acid and sugar concentration of grape juice and temperature on accumulation of acetic acid during yeast fermentation. J Ferment Technol 62:515-521

Murat M-L, Masneuf I, Darriet P, Lavigne V, Tominaga T, Dubourdieu D (2001) Effect of the Saccharomyces cerevisiae yeast strains on the liberation of volatile thiols in Sauvignon blanc wines. Am J Enol Vitic 52:136-139

Ochando T, Mouret J-R, Humbert-Goffard A, Sablayrolles J-M, Farines V (2016) Impact of initial lipid content and oxygen supply on alcoholic fermentation in champagne-like musts. Food Res Int 98:87-94. https://doi. org/10.1016/j.foodres.2016.11.010

Parks LW, Adams BG (1978) Metabolism of sterols in yeast. CRC Crit Rev Microbiol 6:301-341. https://doi.org/10.3109/10408417809090625

Peris D, Pérez-Torrado R, Hittinger CT, Barrio E, Querol A (2018) On the origins and industrial applications of Saccharomyces cerevisiae $\times$ Saccharomyces kudriavzevii hybrids. Yeast 35:51-69. https://doi.org/10.1002/yea.3283

Peter J, De Chiara M, Friedrich A, Yue J-X, Pflieger D, Bergström A, Sigwalt A, Barre B, Freel K, Llored A, Cruaud C, Labadie K, Aury J-M, Istace B, Lebrigand K, Barbry P, Engelen S, Lemainque A, Wincker P, Liti G, Schacherer J (2018) Genome evolution across 1011 Saccharomyces cerevisiae isolates. Nature 556:339-344. https://doi.org/10.1038/s41586-018-0030-5

Pinu FR, Edwards PJB, Jouanneau S, Kilmartin PA, Gardner RC, Villas-Boas SG (2014) Sauvignon blanc metabolomics: grape juice metabolites affecting the development of varietal thiols and other aroma compounds in wines. Metabolomics 10:556-573. https://doi.org/10.1007/s11306-013-0615-9

Pronk JT, Wenzel TJ, Luttik MAH, Klaassen CCM, Scheffers WA, Steensma HY, van Dijken JP (1994) Energetic aspects of glucose metabolism in a pyruvate-dehydrogenase-negative mutant of Saccharomyces cerevisiae. Microbiology 140:601-610. https://doi.org/10.1099/00221287-140-3-601 Remize F, Andrieu E, Dequin S (2000) Engineering of the pyruvate dehydrogenase bypass in Saccharomyces cerevisiae: role of the cytosolic $\mathrm{Mg}(2+)$ and mitochondrial $\mathrm{K}(+)$ acetaldehyde dehydrogenases Ald6p and Ald4p in acetate formation during alcoholic fermentation. Appl Environ Microbiol 66:3151-3159

Ribéreau-Gayon P, Glories Y, Maujean A, Dubourdieu D (2006) Handbook of enology: the microbiology of wine and vinifications. Wiley, New York

Roland A, Vialaret J, Razungles A, Rigou P, Schneider R (2010) Evolution of S-cysteinylated and S-glutathionylated thiol precursors during oxidation of Melon B. and Sauvignon blanc musts. J Agric Food Chem 58:44064413. https://doi.org/10.1021/jf904164t

Roland A, Schneider R, Razungles A, Cavelier F (2011) Varietal thiols in wine: discovery, analysis and applications. Chem Rev 111:7355-7376. https:// doi.org/10.1021/cr100205b

Roland A, Delpech S, Dagan L, Ducasse M-A, Cavelier F, Schneider R (2016) Innovative analysis of 3-mercaptohexan-1-ol, 3-mercaptohexylacetate and their corresponding disulfides in wine by stable isotope dilution assay and nano-liquid chromatography tandem mass spectrometry. J Chromatogr A 1468:154-163. https://doi.org/10.1016/j.chrom a.2016.09.043

Rollero S, Bloem A, Camarasa C, Sanchez I, Ortiz-Julien A, Sablayrolles J-M, Dequin S, Mouret J-R (2015) Combined effects of nutrients and temperature on the production of fermentative aromas by Saccharomyces cerevisiae during wine fermentation. Appl Microbiol Biotechnol 99:2291-2304. https://doi.org/10.1007/s00253-014-6210-9

Roncoroni M, Santiago M, Hooks DO, Moroney S, Harsch MJ, Lee SA, Richards KD, Nicolau L, Gardner RC (2011) The yeast IRC7 gene encodes a $\beta$-lyase responsible for production of the varietal thiol 4-mercapto-4-methylpentan-2-one in wine. Food Microbiol 28:926-935. https://doi.org/10.1016/j. fm.2011.01.002

Saharan RK, Kanwal S, Sharma SC (2010) Role of glutathione in ethanol stress tolerance in yeast Pachysolen tannophilus. Biochem Biophys Res Commun 397:307-310. https://doi.org/10.1016/j.bbrc.2010.05.107

Saint-Prix F, Bonquist L, Dequin S (2004) Functional analysis of the ALD gene family of Saccharomyces cerevisiae during anaerobic growth on glucose: the NADP+-dependent Ald6p and Ald5p isoforms play a major role in acetate formation. Microbiology 150:2209-2220. https://doi.org/10.1099/ mic.0.26999-0

Salvadó Z, Arroyo-López FN, Guillamón JM, Salazar G, Querol A, Barrio E (2011) Temperature adaptation markedly determines evolution within the genus Saccharomyces. Appl Environ Microbiol 77:2292-2302. https://doi. org/10.1128/AEM.01861-10

Sampaio JP, Goncalves P (2008) Natural populations of Saccharomyces kudriavzevii in Portugal are associated with oak bark and are sympatric with $S$. cerevisiae and S. paradoxus. Appl Environ Microbiol 74:2144-2152. https:// doi.org/10.1128/AEM.02396-07

Subileau M, Schneider R, Salmon J-M, Degryse E (2008) Nitrogen catabolite repression modulates the production of aromatic thiols characteristic of Sauvignon Blanc at the level of precursor transport. FEMS Yeast Res 8:771-780. https://doi.org/10.1111/j.1567-1364.2008.00400.x

Swiegers JH, Pretorius IS (2007) Modulation of volatile sulfur compounds by wine yeast. Appl Microbiol Biotechnol 74:954-960. https://doi. org/10.1007/s00253-006-0828-1

Tesnière C, Delobel P, Pradal M, Blondin B (2013) Impact of nutrient imbalance on wine alcoholic fermentations: nitrogen excess enhances yeast cell death in lipid-limited must. PLoS ONE 8:1-11. https://doi.org/10.1371/ journal.pone.0061645

Thibon C, Marullo P, Claisse O, Cullin C, Dubourdieu D, Tominaga T (2008) Nitrogen catabolic repression controls the release of volatile thiols by Saccharomyces cerevisiae during wine fermentation. FEMS Yeast Res 8:1076-1086. https://doi.org/10.1111/j.1567-1364.2008.00381.x

Thurston PA, Taylor R, Ahvenainen J (1981) Effects of linoleic acid supplements on the synthesis by yeast of lipids and acetate esters. J Inst Brew 87:92-95. https://doi.org/10.1002/j.2050-0416.1981.tb03995.x

Van Der Berg MA, Steensma HY (1995) ACS2, a Saccharomyces cerevisiae gene encoding acetyl-coenzyme A synthetase, essential for growth on glucose. Eur J Biochem 231:704-713. https://doi.org/10.1111/j.14321033.1995.0704d.x 
Varela C, Torrea D, Schmidt SA, Ancin-Azpilicueta C, Henschke PA (2012) Effect of oxygen and lipid supplementation on the volatile composition of chemically defined medium and Chardonnay wine fermented with Saccharomyces cerevisiae. Food Chem 135:2863-2871. https://doi. org/10.1016/j.foodchem.2012.06.127

Verstrepen KJ, Van Laere SDM, Vanderhaegen BMP, Derdelinckx G, Dufour J-P, Pretorius IS, Winderickx J, Thevelein JM, Delvaux FR (2003) Expression levels of the yeast alcohol acetyltransferase genes ATF1, Lg-ATF1, and ATF2 control the formation of a broad range of volatile esters. Appl Environ Microbiol 69:5228-5237. https://doi.org/10.1128/ AEM.69.9.5228-5237.2003
Warringer J, Zörgö E, Cubillos FA, Zia A, Gjuvsland A, Simpson JT, Forsmark A, Durbin R, Omholt SW, Louis EJ, Liti G, Moses A, Blomberg A (2011) Trait variation in yeast is defined by population history. PLoS Genet 7:1-15. https://doi.org/10.1371/journal.pgen.1002111

\section{Submit your manuscript to a SpringerOpen ${ }^{\circ}$ journal and benefit from:}

- Convenient online submission

- Rigorous peer review

- Open access: articles freely available online

- High visibility within the field

- Retaining the copyright to your article

Submit your next manuscript at $\boldsymbol{\nabla}$ springeropen.com 